\section{9-45-1, a Capsicum annuum Pepper Germplasm Containing High Concentrations of Capsinoids}

\author{
Robert L. Jarret ${ }^{1}$ \\ USDA/ARS/PGRU, 1109 Experiment Street, Griffin, GA 30223 \\ Jason Bolton and L. Brian Perkins \\ Department of Food Science and Human Nutrition, University of Maine, \\ Orono, ME 04469-5735
}

Additional index words. capsiate, 4-hydroxy-3-methoxybenzyl (E)-8-methyl-6-nonenoate, CAS No. 205687-01-0, dihydrocapsiate, 4-hydroxy-3-methoxybenzyl 8-methylnonanoate, CAS No. 205687-03-2

Germplasm release 509-45-1 is a smallfruited Capsicum annuum L. pepper released in 2013 by the Agricultural Research Service (ARS) of the U.S. Department of Agriculture (USDA). Fruit of 509-45-1 contain high concentrations of capsiate [(4-hydroxy-3methoxybenzyl (E)-8-methyl-6-nonenoate/ CAS No. 205687-01-0] and dihydrocapsiate (4hydroxy-3-methoxybenzyl 8-methylnonanoate/ CAS No. 205687-03-2) in both immature and mature fruit. Concentrations of total capsinoids in immature fruit of 509-45-1 exceeded $1000 \mathrm{ug} \cdot \mathrm{g}^{-1}$ fresh weight (FW), in the absence of capsaicinoids, in 2011. The release of 509-45-1 will provide researchers and plant breeders with a new source of capsinoids, thus facilitating the production of and further research on these non-pungent biologically active compounds.

\section{Origin}

The pungent capsaicinoids, vanillylamide moieties with $\mathrm{C}_{9}-\mathrm{C}_{11}$ branched chain fatty acids, exhibit various beneficial forms of biological activity. However, their use as ingredients in certain foods and pharmaceuticals has been limited by the very characteristic that makes them popular as a spice-pungency. The non-pungent capsinoids are analogs of capsaicinoids and were first isolated from the sweet pepper cultivar CH-19 (Kobata et al., 1998). Capsinoids offer similar types of biological activity as found in capsaicinoids in the absence of pungency (Rosa et al., 2002).

\footnotetext{
Received for publication 22 Oct. 2013. Accepted for publication 26 Nov. 2013.

This work was supported in part by USDA/NRI Grant No. 2006-35503-17179 and Hatch Grant No. ME08555-07.

We gratefully acknowledge the technical assistance of Mr. Chris Tatum, Dr. Satyavan Singh, and Valerie Antonio for the production of fruit, sample preparation/extraction, and analysis of capsaicinoids and capsinoids.

This is Maine Agriculture and Experiment Station Publication No. 3352.

${ }^{1}$ To whom reprint requests should be addressed; e-mail bob.jarret@ars.usda.gov.
}

Known capsinoids include capsiate, dihydrocapsiate, and nordihydrocapsiate (Kobata et al., 1999). In addition to antioxidant activity (Rosa et al., 2002), capsinoids enhance adrenal catecholamine secretion, promote energy metabolism, and suppress body fat accumulation (Masuda et al., 2003; Onuki et al., 2001; Sasahara et al., 2010; Tani et al., 2004). Their thermogenic and metabolic effects have been noted as supportive of their potential role as an adjunct weight loss aid (Josse et al., 2010). Tanaka et al. (2009) screened 35 lines of Capsicum (including five species) and noted that all species evaluated had one or more genotypes that produced capsiate, the highest concentrations being found in fruit of $C$. baccatum var. praetermissum and C. chinense.

Interest in capsinoids resulted in a screening of 120 randomly selected PIs for the occurrence of capsinoids (capsiate and dihydrocapsiate) in 2005. During this screening, low concentrations of capsinoids were detected in bulked fruit harvested from plants of PI 645509. Typical fruit of PI 645509 are small and extremely pungent. In 2006, 100 plants of PI 645509 were grown in the field in Griffin, GA, and the fruit of individual plants were harvested and analyzed for total capsinoids and capsaicinoids. A single plant was subsequently identified that had fruit with a low $\left(\approx 300 \mathrm{ug} \cdot \mathrm{g}^{-1} \mathrm{FW}\right)$ concentration of total capsinoids and non-detectable amounts of capsaicinoids (as determined by high-performance liquid chromatography). This plant was selfpollinated and its progeny (100 plants) were grown in the field in 2007 and the single plant selection process for elevated concentrations of capsinoids repeated. Further selections were conducted in 2008, 2009, and 2010. In 2011, a single plant was identified bearing immature fruit that contained greater than $1000 \mathrm{ug} \cdot \mathrm{g}^{-1} \mathrm{FW}$ capsinoids with no detectable capsaicinoids. Seed harvested from this plant were designated 509-45-1.

\section{Description and Performance}

Fruit and plants of 509-45-1 are homogeneous. Plants of 509-45-1 are semispreading with numerous basal branches that have an erect attitude. The leaf shape is lanceolate, medium green [Royal Horticultural Society Color Charts (RHS) 137B, <http://www.rhs. org.uk/Plants/RHS-Publications/RHS-colourcharts $>$ ] in color with slight pubescence present on the leaves and petioles. Plants of 509-45-1 can reach a height of $80 \mathrm{~cm}$ in the field over the course of a 120-d growing season and flower and bear fruit continuously until killed by frost. The corolla color is white on flowers borne one per leaf axil. Styles are exserted. Fruit are scattered throughout the plant, which routinely produces many hundreds of fruit over a growing season. A typical 509-45-1 fruit is $\approx 28 \mathrm{~mm}$ in length, $0.8 \mathrm{~cm}$ in diameter, trapezoidal in shape (longitudinal section), round in cross-section, and weighs $\approx 0.6 \mathrm{~g}$. Fruit have a mean of two locules and a flesh thickness of $\approx 1 \mathrm{~mm}$. Fruit may be pendent, erect, or intermediate. The fruit base is rounded with a blunt apex. Immature fruit are a medium green color (RHS 137C). Mature fruit are a dark red (RHS 45A), moderately glossy, and with a moderately intense flavor. Anthocyanin is absent in seedlings, leaves, calyxes, and fruit and weakly present on stems, at nodes, and on pedicels. Capsaicin and its analogs are not present in fruit of 509-45-1. Concentrations of fruit capsinoids increase rapidly $\approx 10 \mathrm{~d}$ post-anthesis 
and peak in the immature green stage of maturity, declining thereafter. Immature green fruit of 509-45-1 can be expected to contain 750 to greater than $1000 \mathrm{ug} \cdot \mathrm{g}^{-1} \mathrm{FW}$ total capsinoids (Table 1). Concentrations of capsinoids in greenhouse-grown fruit are often substantially (greater than 50\%) reduced when compared with field-grown fruit (data not shown).

\section{Availability}

Small quantities of seed of 509-45-1 are available for research purposes from Dr. R.L. Jarret, USDA/ARS, 1109 Experiment Street, Griffin, GA 30223, 770/228-7303. Genetic material of this release (PI 669378) has been deposited in the National Plant Germplasm System and is available for research purposes, including the development and commercialization of new varieties/cultivars. It is requested that appropriate recognition be made if 509-45-1 contributes to research, the production of capsinoids, or to the development of breeding lines or cultivars.

\section{Literature Cited}

Josse, A.R., S.S. Sherriffs, A.M. Holwerda, R. Andrews, A.W. Staples, and S.M. Phillips. 2010. Effects of capsinoid ingestion on energy expenditure and lipid oxidation at rest and during exercise. Nutrition \& Metabolism 7:65. $<\mathrm{http}$ ://www.nutritionandmetabolism.com/ content/7/1/65>.

Kobata, K., K. Sutoh, T. Todo, S. Yazawa, K. Iwai, and T. Watanabe. 1999. Nordihydrocapsiate, a new capsinoid from the fruits of a nonpungent pepper, Capsicum annuum. J. Nat. Prod. 62:335336.

Kobata, K., T. Tomoko, S. Yazawa, K. Iwai, and T. Watanabe. 1998. Novel capsaicinoid-like substances, capsiate and dihydrocapsiate, from the fruits of a nonpungent cultivar, $\mathrm{CH}-19$ Sweet, of pepper (Capsicum annuиm L.). J. Agr. Food Chem. 46:1695-1697.

Masuda, Y., S. Haramizu, K. Oki, K. Ohnuki, T. Watanabe, S. Yazawa, T. Kawada, S. Hashizume, and T. Fushiki. 2003. Upregulation of uncoupling proteins by oral administration of capsiate, a non-pungent capsaicin analog. J. Appl. Phys. 95:2408-2415.

Onuki, K., S. Hararmizu, T. Watanabe, S. Yazawa, and T. Fushiki. 2001. Administration of capsiate, a non-pungent capsaicin analog, promotes energy metabolism and suppresses body fat accumulation in mice. Biosci. Biotechnol. Biochem. 65:2375-2382.

Rosa, A., M. Deiana, V. Casu, S. Paccagnini, G. Appendino, M. Ballero, and M.A. Dessi. 2002. Antioxidant activity of capsinoids. J. Agr. Food Chem. 50:7396-7401.

Sasahara, I., Y. Furuhata, Y. Iwasaki, N. Inoue, H. Sato, T. Watanabe, and M. Takahashi. 2010. Assessment of the biological similarity of three capsaicin analogs (capsinoids) found in nonpungent chili pepper (CH-19 Sweet) fruits Biosci. Biotechnol. Biochem. 74:274-278.

Singh, S., R. Jarret, V. Russo, G. Majetich, J. Shimkus, R. Bushway, and B. Perkins. 2009 Determination of capsinoids by HPLC-DAD in Capsicum species. J. Agr. Food Chem. 57: 3452-3457.

Tanaka, Y., M. Hosokawa, K. Otsu, T. Watanabe, and S. Yazawa. 2009. Assessment of capsiconinoid composition, nonpungent capsaicinoid analogues, in Capsicum cultivars. J. Agr. Food Chem. 57:5407-5412.

Tani, Y., T. Fujioka, M. Sumioka, Y. Furuichi, H. Hamada, and T. Watanabe. 2004. Effects of capsinoid on serum and liver lipids in hyperlipidemic rats. J. Nut. Sci. and Vit. 50:351-355. 